REVIEW ARTICLE

\author{
R. Rahme \\ R. Moussa
}

\section{The Modic Vertebral Endplate and Marrow Changes: Pathologic Significance and Relation to Low Back Pain and Segmental Instability of the Lumbar Spine}

\begin{abstract}
SUMMARY: Two decades following their description, the significance of Modic vertebral endplate and marrow changes remains a matter of debate. These changes are closely related to the normal degenerative process affecting the lumbar spine, and their prevalence increases with age. However, the exact pathogenesis underlying these changes and their relation to segmental instability of the lumbar spine and to low back pain remain unclear. In this paper, we review the literature relevant to this topic and discuss the currently available evidence regarding the pathologic and clinical significance of Modic changes.
\end{abstract}

D egenerative vertebral endplate and subchondral bone marrow changes were first noted on MR imaging by de Roos et al in $1987 .{ }^{1}$ A formal classification was subsequently provided by Modic et al in $1988,{ }^{2}$ based on a study of 474 patients, most of whom had chronic low back pain (LBP). These authors described 2 types of endplate and marrow changes:

Type 1 changes (Fig 1) were hypointense on T1-weighted imaging (T1WI) and hyperintense on T2-weighted imaging (T2WI) and were shown to represent bone marrow edema and inflammation.

Type 2 changes (Fig 2) were hyperintense on T1WI and isointense or slightly hyperintense on T2WI and were associated with conversion of normal red hemopoietic bone marrow into yellow fatty marrow as a result of marrow ischemia., ${ }^{1,2}$

Modic type 3 changes (Fig 3 ) were subsequently described as hypointense on both T1WI and T2WI and were thought to represent subchondral bone sclerosis. ${ }^{3}$ Mixed-type 1/2 and 2/3 Modic changes have also been reported, suggesting that these changes can convert from one type to another and that they all present different stages of the same pathologic process. ${ }^{4}$ The absence of Modic changes, a normal anatomic appearance, has often been designated Modic type $0 .^{5}$

\section{Epidemiology}

The prevalence of Modic changes among patients with degenerative disk disease (DDD) of the lumbar spine varies between $19 \%$ and $59 \%$, with type 1 and 2 changes being the most common and type 3 and mixed-type changes being relatively rare. ${ }^{1-4,6-14}$ There is disagreement as to whether Modic type 1 or 2 changes are most prevalent in this patient population. Although several series, including the original study of Modic et $\mathrm{al}^{2}$ have shown that type 2 changes are the most frequent and may account for up to $90 \%$ of Modic changes, ${ }^{1-3,9,10,12,13}$ other studies have suggested that type 1 changes may be more common and may constitute up to $68 \%$ of Modic changes in these patients. ${ }^{4,711}$ Such differences in the quoted prevalence

From the Department of Neurosurgery, Saint-Joseph University and Hôtel-Dieu de France, Beirut, Lebanon.

Please address correspondence to Ralph Rahme, MD, Department of Neurosurgery, Hôtel-Dieu de France, Ashrafieh, Beirut, Lebanon; e-mail: rrahme@waln.org

DOl 10.3174/ajnr.A0925 of Modic changes and the relative frequency of each Modic type are most likely the result of sampling errors and variations among the studied populations. Modic changes are most common at L4-L5 and L5-S1 $1^{4,10,12,13}$ and are associated with increasing age. ${ }^{10,12}$ These changes usually occur adjacent to degenerated or herniated intervertebral disks. ${ }^{1-3,9,10,15}$

Modic changes are uncommon in asymptomatic individuals without DDD. ${ }^{6,16,17}$ In the series of Toyone et al, ${ }^{6}$ only $9.6 \%$ of patients without DDD had such changes. Weishaupt et $\mathrm{al}^{16}$ reported a prevalence of $3 \%-10 \%$ among 60 asymptomatic volunteers 20-50 years of age. In particular, type 1 changes were only seen by 1 radiologist in 1 volunteer in 1 of 300 lumbar intervertebral spaces. In a population-based sample of four hundred twelve 40 -year old Danes, Kjaer et al ${ }^{17}$ observed Modic changes in the lumbar spines of $9.6 \%$ of subjects without DDD and $34.1 \%$ of those with DDD.

\section{Differential Diagnosis}

Intervertebral disk space infections typically give rise to vertebral marrow edema, manifesting as areas of low signal intensity on T1WI and high signal intensity on T2WI, thereby mimicking type 1 Modic changes. ${ }^{18,19}$ Moreover, contrast enhancement in the disk and endplates may occur in both conditions. ${ }^{18-21}$ However, because of desiccation and dehydration, the disk often appears normal or hypointense on T2WI in DDD, whereas its T2WI signal intensity is typically increased in spondylodiskitis. ${ }^{18,19,21}$ Also, the vertebral endplates are usually preserved in DDD rather than eroded or destroyed as seen in disk space infection. ${ }^{18,21}$ Finally, the presence of paraspinal or epidural inflammation and/or collection should orient the diagnosis toward an infectious process. ${ }^{18,20,21}$ In addition to these imaging considerations, the clinical presentation and context and the results of laboratory tests such as erythrocyte sedimentation rate and C-reactive protein (CRP) can help differentiate between the 2 entities. ${ }^{18}$ In particular, the CRP appears to be a very reliable indicator of disk space infection, being raised in up to $100 \%$ of patients at the time of diagnosis. ${ }^{18}$

\section{Pathology and Pathogenesis}

In their original study, Modic et $\mathrm{al}^{2}$ analyzed histopathologic sections from 3 patients with type 1 changes and 3 patients with type 2 changes. The authors found that type 1 changes 

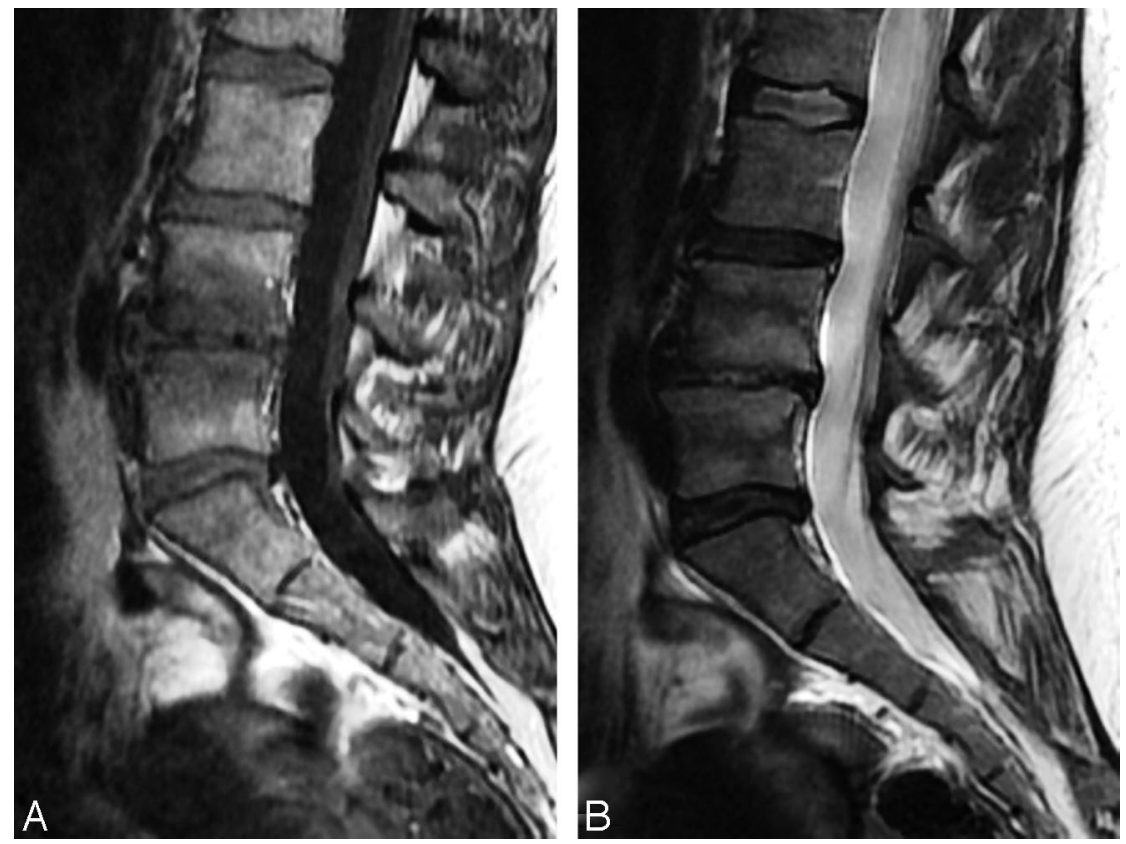

Fig 1. Modic type 1 changes are hypointense on T1WI $(A)$ and hyperintense on T2WI $(B)$.
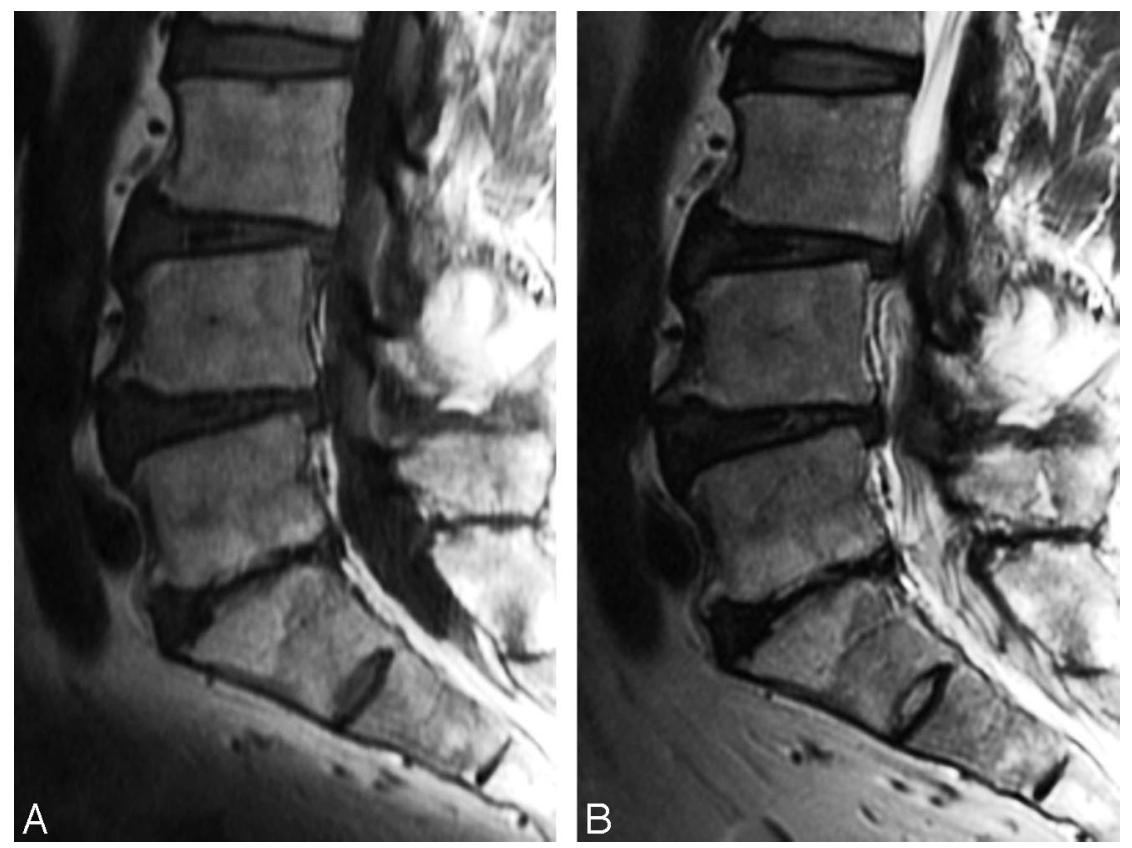

Fig 2. Modic type 2 changes are hyperintense on T1WI $(A)$ and isointense or hyperintense on T2WI $(B)$.

were associated with disruption and fissuring of endplates and formation of a fibrovascular granulation tissue. In contrast, type 2 changes were associated with fatty degeneration of the red marrow and its replacement by yellow marrow. They concluded that type 1 changes correspond to the inflammatory stage of DDD and indicate an ongoing active degenerative process, whereas type 2 changes represent the fatty stage of DDD and are related to a more stable and chronic process. These authors later postulated that type 3 changes represent the sclerotic stage of DDD. ${ }^{3}$

According to Modic, ${ }^{15}$ the altered signal intensity detected by MR imaging is not, in and of itself, the causal pathologic process but rather a reflection of the causal process, which is some type of biomechanical stress or instability. Karchevsky et $\mathrm{al}^{10}$ concluded that these changes likely represent a response of the bone marrow to the degenerative process involving the disk. In fact, type 1 changes have been shown to develop in $8 \%$ of patients following diskectomy and $40 \%$ following chemonucleolysis, which may be viewed as models of accelerated disk degeneration. ${ }^{15}$ Kokkonen et $\mathrm{al}^{22}$ observed a strong positive correlation between Modic changes and disk degeneration and proposed that endplate degeneration is more likely to be a sequel in the process of disk degeneration than a factor contributing to disk damage.

Crock $^{23}$ suggested that repeated trauma to intervertebral disks results in the production of inflammatory mediators in the nucleus pulposus and that diffusion of such toxic chemicals through vertebral endplates could result in a local inflammatory reaction resulting in LBP. Brown et $\mathrm{al}^{24}$ studied specimens of intervertebral disks, vertebral endplates, and adjacent cancellous bone they obtained during anterior diskectomy and fusion from patients with chronic LBP and DDD. They 

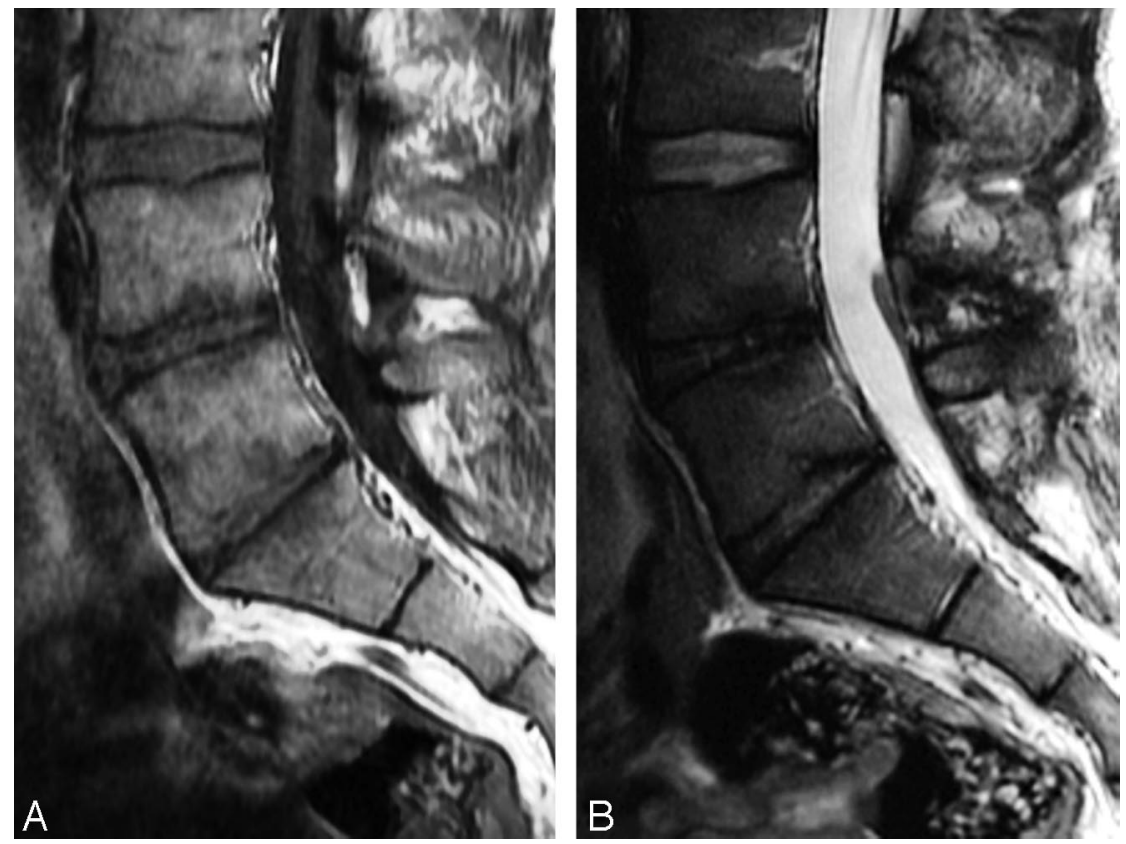

Fig 3. Modic type 3 changes are hypointense on both T1WI $(A)$ and T2WI $(B)$.

observed cracks and defects in the vertebral endplates, with increases in vascular density and the number of sensory nerve fibers, and hypothesized that such changes could represent a means of increasing disk nourishment and could be a source of LBP in patients with DDD. Burke et $\mathrm{al}^{25}$ observed a greater increase in proinflammatory mediators such as interleukin-6, interleukin-8, and prostaglandin E-2 in the disks of patients with type 1 Modic changes undergoing fusion for LBP than in those of patients undergoing diskectomy for sciatica. These authors proposed that the production of proinflammatory mediators within the nucleus pulposus may be a major factor in the genesis of diskogenic LBP. Vital et $\mathrm{al}^{26}$ concluded that Modic type 1 changes correspond to edema of vertebral endplates and subchondral bone. This edema could correspond to microfractures of cancellous bone and endplate cracks accompanied by an increased vascular density along with an increase in the number of nerve endings and in the levels of proinflammatory chemical mediators, and these vascular and inflammatory changes would follow the initial mechanical phenomena.

Schmid et $\mathrm{al}^{9}$ found a positive correlation between the presence and extent of Modic changes and the amount of cartilage in the extruded disk in patients undergoing lumbar microdiskectomy and concluded that these changes may result from avulsion-type disk herniation. Ohtori et $\mathrm{al}^{27}$ found that the cartilaginous endplates of patients with Modic changes had more protein gene product (PGP) 9.5 immunoreactive nerve fibers and tumor necrosis factor (TNF) immunoreactive cells than those with normal endplates. PGP 9.5 immunoreactivity was seen exclusively in patients with diskogenic LBP, whereas TNF immunoreactivity was seen in both patients with LBP and healthy controls. In addition, the number of TNF immunoreactive cells in endplates with Modic type 1 changes was higher than those with type 2 changes. The authors concluded that inflammatory cytokines and nerve ingrowth into vertebral endplates may be a cause of diskogenic LBP and that type 1 changes, representing more active inflammation, seem to be mediated by proinflammatory cytokines, whereas type 2 and 3 changes could be more quiescent stages of the process.
In a randomized controlled trial, Korhonen et $\mathrm{al}^{28}$ found that infliximab, a monoclonal antibody against TNF- $\alpha$, was no more effective than placebo in the treatment of disk herniation-induced sciatica. However, the authors noted a trend toward better results in the infliximab group when a Modic change was colocalized at the symptomatic level. Fayad et $\mathrm{al}^{29}$ found that patients with chronic LBP and predominantly type 1 inflammatory Modic changes had better short-term relief of symptoms following intradiskal steroid injection than those with predominantly type 2 changes, which further supports the inflammatory nature of Modic type 1 changes and the role of inflammation in the generation of LBP.

\section{Modic Changes and LBP}

Kjaer et $\mathrm{al}^{17}$ suggested that Modic changes constitute the crucial element in the degenerative process around the disk in relation to LBP and clinical findings. They demonstrated that DDD on its own was a fairly quiet disorder, whereas DDD with Modic changes was much more frequently associated with clinical symptoms. Most authors agree that, among Modic changes, type 1 changes are the ones most strongly associated with LBP. ${ }^{6,8,13-15}$ In a study of 74 patients with DDD, Toyone et $\mathrm{al}^{6}$ observed that $73 \%$ of patients with type 1 changes had LBP as opposed to only $11 \%$ of those with type 2 changes. Mitra et $\mathrm{al}^{8}$ found a positive trend between the evolution of type 1 Modic changes into type 2 changes and the improvement of symptoms. In addition, they observed that patients in whom type 1 changes increased were clinically worsened. Albert and Manniche ${ }^{14}$ reported a strong association between Modic changes and LBP as $60 \%$ of patients with Modic changes but only $20 \%$ of those without such changes had LBP. These authors also showed that type 1 changes were more strongly associated with LBP than type 2 changes. In a study of 228 Finnish middle-aged male workers, Kuisma et $\mathrm{al}^{13}$ found that Modic changes at L5-S1, especially type 1 changes and extensive lesions, were strongly associated with pain symptoms and LBP.

The relationship between Modic changes and diskogenic 
LBP remains a matter of debate. ${ }^{4,7,22,30}$ Braithwaite et $\mathrm{al}^{4}$ and Weishaupt et $\mathrm{al}^{7}$ showed that Modic changes have a very high specificity (96\%-96.8\%) and positive predictive value (88\%$91.3 \%$ ) for pain reproduction during diskography in patients with chronic LBP. In contrast, other MR imaging findings such as advanced disk degeneration and high-intensity zones were found to be much less specific for diskogenic LBP. Weishaupt et $\mathrm{al}^{7}$ further demonstrated that moderate and severe Modic changes (ie, those extending over $25 \%$ or more of the vertebral height) have a specificity and positive predictive value of $100 \%$ for a concordant pain response on diskography. The findings of these authors have been challenged by those of Sandhu et $\mathrm{al}^{30}$ and Kokkonen et $\mathrm{al},{ }^{22}$ who failed to demonstrate any significant association between the presence of Modic changes and pain provocation during diskography in patients with chronic LBP. Given the limited sample sizes in these studies and their conflicting results, no conclusions can be drawn at this time with certainty regarding the relationship between Modic changes and diskogenic LBP.

\section{Modic Changes and Segmental Instability}

In the study of Toyone et $\mathrm{al},{ }^{6} 70 \%$ of patients with type 1 Modic changes but only $16 \%$ of those with type 2 changes were found to have segmental hypermobility, defined as a sagittal translation of $3 \mathrm{~mm}$ or more on dynamic flexion-extension films. The authors concluded that patients with chronic LBP and type 1 Modic changes had more frequent instability requiring arthrodesis than those with type 2 changes. Their results were challenged by those of Bräm et al, ${ }^{31}$ who did not find any relationship between type 1 Modic changes and lumbar instability by using the same radiologic criteria. A major limitation of these studies is their reliance on a radiologic definition of lumbar instability for which a consensus has to exist. ${ }^{32}$

The relationship between Modic type 1 changes and segmental instability is mostly supported by indirect evidence coming from outcome studies following lumbar fusion. ${ }^{26,33-36}$ In a study assessing osseous union following lumbar fusion in 33 patients, Lang et $\mathrm{al}^{33}$ found that all 19 patients with solid fusion had type 2 Modic changes, whereas 10 of 14 patients with nonunion had type 1 changes. They concluded that the persistence of type 1 Modic changes after fusion suggests pseudarthrosis. Buttermann et $\mathrm{al}^{34}$ similarly observed that nonfusion was associated predominantly with the persistence of type 1 Modic changes. In a study of 56 patients treated with anterior lumbar interbody fusion for LBP, Chataigner et $\mathrm{al}^{35}$ found that patients with type 1 Modic changes had much better outcomes than those with isolated DDD and those with type 2 changes, in whom the results were generally poor. Vital et $\mathrm{al}^{26}$ assessed clinical and radiologic outcomes following instrumented posterolateral fusion in 17 patients with chronic LBP and type 1 Modic changes. Six months later, all type 1 changes had converted, $76.5 \%$ into type 2 changes and $23.5 \%$ back to normal, and clinical improvement was seen in all patients. They concluded that fusion accelerates the course of type 1 Modic changes probably by correcting the mechanical instability and that these changes appear to be a good indicator of satisfactory surgical outcome after arthrodesis. In a study of 60 patients with severe chronic LBP and single-level DDD treated with instrumented fusion, Esposito et $\mathrm{al}^{36}$ showed that patients with type 1 Modic changes had excellent results and improved much better than patients with type 2 changes whose clinical outcome was poor.

\section{Natural History}

Braithwaite et $\mathrm{al}^{4}$ suggested that Modic changes can convert from one type to another and that they all present different stages of the same pathologic process. Mixed-type changes are assumed to develop before conversion to one of the true Modic types. ${ }^{4,26}$ In their original study, Modic et $\mathrm{al}^{2}$ followed 16 patients longitudinally. Among the 6 patients with type 1 Modic changes, 5 patients showed at least a partial conversion into type 2 within 14 months to 3 years, whereas the remaining patient demonstrated reverse transformation into Modic type 0 . In contrast, none of the 10 patients with type 2 Modic changes showed a change during the 2- to 3-year follow-up period. The authors concluded that type 2 changes are stable and unchangeable with time, whereas type 1 changes are unstable. This view was supported by a greater prevalence of type 2 changes in their study.

It is generally agreed that type 1 changes are unstable lesions. ${ }^{2,8,15,26}$ Vital et $\mathrm{al}^{26}$ demonstrated that all type 1 changes converted into either type 2 changes or back to normal within 6 months following lumbar fusion, which paralleled clinical improvement in all patients. In a longitudinal study of 44 nonoperated patients with LBP and sciatica followed for 12-72 months, Mitra et $\mathrm{al}^{8}$ found that $92 \%$ of type 1 changes either converted wholly or partially into type 2 changes (52\%) or became more extensive $(40 \%)$ and that only $8 \%$ of these changes remained the same. They concluded that type 1 Modic changes are dynamic lesions that, in most cases, either increase in size or convert into type 2 changes.

The stability of type 2 changes has been recently questioned by several authors. ${ }^{5,12,14}$ Kuisma et $\mathrm{al}^{12}$ studied the natural history of Modic changes in 60 nonoperated patients with sciatica. They found that $14 \%$ of Modic changes evolved into another type within 3 years, $80 \%$ of the conversions being from type 2 to either type 1 or mixed type $1 / 2$. They also found that nonconverted Modic changes increased in size and that new Modic changes developed adjacent to degenerated disks in $6 \%$ of patients, $77 \%$ of these new changes being either type 1 or mixed type $1 / 2$. They concluded that type 2 changes may be less stable than previously assumed and speculated that an acute ongoing inflammatory process in some type 2 changes causes conversion of yellow to red marrow, which suggests superimposed changes such as continued or accelerated degeneration, a view shared by Modic. ${ }^{15}$ In a study of 166 nonoperated patients with sciatica undergoing repeat MR imaging at 14 months, Albert and Manniche ${ }^{14}$ found that the prevalence of Modic changes increased from $9 \%$ at baseline to $29 \%$ at follow-up, all new changes developing at the level of the previous disk herniation. In addition, many patients with preexistent Modic changes developed additional type 1 changes. They concluded that lumbar disk herniation was a strong risk factor for developing Modic changes, especially type 1, during the following year. Marshman et $\mathrm{al}^{5}$ reported on 2 patients who showed reverse transformation of type 2 Modic changes into type 1 changes despite a sustained chronic LBP severity. The authors concluded that type 2 changes are neither as stable nor as quiescent as originally believed and that Modic types 1 
and 2 are instead interchangeable and equipotent in symptom-generating capacity.

\section{Conclusion}

From this review, it appears that Modic changes are dynamic markers of the normal age-related degenerative process affecting the lumbar spine. These lesions can convert from one type to another with time, with mixed-type changes probably representing the intermediate stages in this conversion. Type 1 changes are likely to be inflammatory in origin and seem to be strongly associated with active low back symptoms and segmental instability, thus reflecting a state of active degeneration and biomechanical instability of the lumbar spine. Accordingly, these changes appear to predict an excellent outcome following lumbar fusion. In contrast, type 2 changes are less clearly associated with LBP and seem to indicate a more biomechanically stable state, though superimposed stress may occasionally cause their reverse conversion into type 1 changes. Finally, the exact nature and pathogenetic significance of type 3 changes remains largely unknown.

\section{References}

1. de Roos A, Kressel H, Spritzer C, et al. MR imaging of marrow changes adjacent to end plates in degenerative lumbar disk disease. AJR Am J Roentgenol 1987;149:531-34

2. Modic MT, Steinberg PM, Ross JS, et al. Degenerative disk disease: assessment of changes in vertebral body marrow with MR imaging. Radiology 1988;166:193-99

3. Modic MT, Masaryk TJ, Ross JS, et al. Imaging of degenerative disk disease. Radiology 1988;168:177-86

4. Braithwaite I, White J, Saifuddin A, et al. Vertebral end-plate (Modic) changes on lumbar spine MRI: correlation with pain reproduction at lumbar discography. Eur Spine J 1998;7:363-68

5. Marshman LA, Trewhella M, Friesem T, et al. Reverse transformation of Modic type 2 changes to Modic type 1 changes during sustained chronic low-back pain severity: report of two cases and review of the literature. J Neurosurg Spine 2007;6:152-55

6. Toyone $\mathrm{T}$, Takahashi K, Kitahara $\mathrm{H}$, et al. Vertebral bone-marrow changes in degenerative lumbar disc disease: an MRI study of 74 patients with low back pain. J Bone Joint Surg Br 1994;76:757-64

7. Weishaupt D, Zanetti M, Hodler J, et al. Painful lumbar disk derangement: relevance of endplate abnormalities at MR imaging. Radiology 2001;218:420-27

8. Mitra D, Cassar-Pullicino VN, McCall IW. Longitudinal study of vertebral type-1 end-plate changes on MR of the lumbar spine. Eur Radiol 2004;14:1574-81

9. Schmid G, Witteler A, Willburger R, et al. Lumbar disk herniation: correlation of histologic findings with marrow signal intensity changes in vertebral endplates at MR imaging. Radiology 2004;231:352-58

10. Karchevsky M, Schweitzer ME, Carrino JA, et al. Reactive endplate marrow changes: a systematic morphologic and epidemiologic evaluation. Skeletal Radiol 2005;34:125-29

11. Kjaer P, Leboeuf-Yde C, Korsholm L, et al. Magnetic resonance imaging and low back pain in adults: a diagnostic imaging study of 40 -year-old men and women. Spine 2005;30:1173-80

12. Kuisma M, Karppinen J, Niinimaki J, et al. A three-year follow-up of lumbar spine endplate (Modic) changes. Spine 2006;31:1714-18
13. Kuisma M, Karppinen J, Niinimäki J, et al. Modic changes in endplates of lumbar vertebral bodies: prevalence and association with low back and sciatic pain among middle-aged male workers. Spine 2007;32:1116-22

14. Albert HB, Manniche C. Modic changes following lumbar disc herniation. Eur Spine J 2007;16:977-82

15. Modic MT. Modic type 1 and type 2 changes. J Neurosurg Spine 2007;6:150-51

16. Weishaupt D, Zanetti M, Hodler J, et al. MR imaging of the lumbar spine: prevalence of intervertebral disk extrusion and sequestration, nerve root compression, end plate abnormalities, and osteoarthritis of the facet joints in asymptomatic volunteers. Radiology 1998;209:661-66

17. Kjaer P, Korsholm L, Bendix T, et al. Modic changes and their associations with clinical findings. Eur Spine J 2006;15:1312-19

18. James SL, Davies AM. Imaging of infectious spinal disorders in children and adults. Eur J Radiol 2006;58:27-40

19. Ross JS, Modic MT. Current assessment of spinal degenerative disease with magnetic resonance imaging. Clin Orthop Relat Res 1992;279:68-81

20. Van Goethem JW, Parizel PM, van den Hauwe L, et al. The value of MRI in the diagnosis of postoperative spondylodiskitis. Neuroradiology 2000;42:580-85

21. Ledermann HP, Schweitzer ME, Morrison WB, et al. MR imaging findings in spinal infections: rules or myths? Radiology 2003;228:506-14

22. Kokkonen SM, Kurunlahti M, Tervonen O, et al. Endplate degeneration observed on magnetic resonance imaging of the lumbar spine: correlation with pain provocation and disc changes observed on computed tomography diskography. Spine 2002;27:2274-78

23. Crock HV. Internal disc disruption: a challenge to disc prolapse fifty years on. Spine 1986;11:650-53

24. Brown MF, Hukkanen MV, McCarthy ID, et al. Sensory and sympathetic innervation of the vertebral endplate in patients with degenerative disc disease. J Bone Joint Surg Br 1997;79:147-53

25. Burke JG, Watson RW, McCormack D, et al. Intervertebral discs which cause low back pain secrete high levels of proinflammatory mediators. J Bone Joint Surg Br 2002;84:196-201

26. Vital JM, Gille O, Pointillart V, et al. Course of Modic 1 six months after lumbar posterior osteosynthesis. Spine 2003;28:715-21

27. Ohtori S, Inoue G, Ito $\mathrm{T}$, et al. Tumor necrosis factor-immunoreactive cells and PGP 9.5-immunoreactive nerve fibers in vertebral endplates of patients with discogenic low back pain and Modic type 1 or type 2 changes on MRI. Spine 2006;31:1026-31

28. Korhonen T, Karppinen J, Paimela L, et al. The treatment of disc-herniationinduced sciatica with infliximab: one-year follow-up results of FIRST II, a randomized controlled trial. Spine 2006;31:2759-66

29. Fayad F, Lefevre-Colau MM, Rannou F, et al. Relation of inflammatory Modic changes to intradiscal steroid injection outcome in chronic low back pain. Eur Spine J 2007;16:925-31

30. Sandhu HS, Sanchez-Caso LP, Parvataneni HK, et al. Association between findings of provocative discography and vertebral endplate signal changes as seen on MRI. J Spinal Disord 2000;13:438-43

31. Bräm J, Zanetti M, Min K, et al. MR abnormalities of the intervertebral disks and adjacent bone marrow as predictors of segmental instability of the lumbar spine. Acta Radiol 1998;39:18-23

32. Nizard RS, Wybier M, Laredo JD. Radiologic assessment of lumbar intervertebral instability and degenerative spondylolisthesis. Radiol Clin North Am 2001;39:55-71

33. Lang P, Chafetz N, Genant HK, et al. Lumbar spinal fusion: assessment of functional stability with magnetic resonance imaging. Spine 1990;15:581-88

34. Buttermann GR, Heithoff KB, Ogilvie JW, et al. Vertebral body MRI related to lumbar fusion results. Eur Spine J 1997;6:115-20

35. Chataigner H, Onimus $M$, Polette A. Surgery for degenerative lumbar disc disease: should the black disc be grafted [in French]? Rev Chir Orthop Reparatrice Appar Mot 1998;84:583-89

36. Esposito P, Pinheiro-Franco JL, Froelich S, et al.. Predictive value of MRI vertebral end-plate signal changes (Modic) on outcome of surgically treated degenerative disc disease: results of a cohort study including 60 patients. Neurochirurgie 2006;52:315-22 